\title{
PACKAGED PHASAR-BASED WAVELENGTH DEMULTIPLEXER WITH INTEGRATED DETECTORS
}

\author{
A.A.M. Staring, C. van Dam, ${ }^{*}+$ J.J.M. Binsma, E.J. Jansen, A.J.M. Verboven, \\ L.J.C. Vroomen, J.F. de Vries, M.K. Smit, ${ }^{*}$ and B.H. Verbeek \\ Philips Optoelectronics Research, Prof. Holstlaan 4, NL-5656 AA Eindhoven, \\ tel. +31-40-2743240, fax. +31-40-2743859, e-mail: \\ staringa@natlab.research.philips.com
}

\begin{abstract}
For the first time, PHASAR-based wavelength demultiplexers with integrated detectors have been packaged in an industry-standard Butterfly-type module. 8-Channel nearly polarisation-independent operation is demonstrated. In addition, $4 \mathrm{~nm}$ tuning is realised.

\section{INTRODUCTION}

The quickest growing market segment in optical telecommunications is that of Wavelength Division Multiplexing (WDM) systems. Presently, these systems find are deployed in high-end point-to-point links, and are constructed from discrete components such as wavelength-specific DFB lasers, modulators, (de-)multiplexers, and receiver photodiodes. As the number of installed WDM systems grows, this technology will penetrate further into the network, which will call for a reduction of the number of separate components, in favour of cost-effective integrated solutions.

On the receiver side of a WDM link, a single module containing a wavelength demultiplexer, photodetectors, and transimpedance amplifiers, is an attractive component. Recently, a number of wavelength demultiplexers with integrated photodetectors have been reported [1], [2], [3], [4], [5]. In addition, both hybrid [6] and monolithic [7] integration of a PHASAR and preamplifiers have been shown, as well as a packaged WDM receiver module containing a pigtailed spectrograph and a separately pigtailed pin-JFET array $[8]$.

In this paper, the first packaged InP PHASAR-based demultiplexer with integrated detectors is presented, using an industry-standard Butterfly module. This is made possible by the compact dimensions of the opto-electronic chip. Nearly polarisation-independent $\mathrm{CW}$ operation is demonstrated for 8 channels with $200 \mathrm{GHz}$ spacing. In addition tuning of the channels is realised over $4 \mathrm{~nm}$.
\end{abstract}

\section{DESIGN}

Polarisation-independent operation is obtained by making use of non-birefringent waveguides [9]. The $8 \times 8$ PHASAR chip, shown in Fig. 1, is designed to have a central wavelength of $1535 \mathrm{~nm}$, a $200 \mathrm{GHz}$ channel spacing, and a $50 \mathrm{~nm}$ free spectral range. Its size is only $1.4 \times 1.3 \mathrm{~mm}^{2}$. To transfer light from the output waveguides to the InGaAs absorption layer, evanescent coupling is employed in the detectors. Using the optimised layer stack shown in Fig. 2, simulation work predicts a better than $99 \%$ coupling efficiency in the $200 \mu \mathrm{m}$ long, $8 \mu \mathrm{m}$ wide detectors.

\footnotetext{
*Department of Electrical Engineering, Delft University of Technology, Delft, The Netherlands
}

${ }^{\ddagger}$ Presently at TNO-FEL, The Hague, The Netherlands 


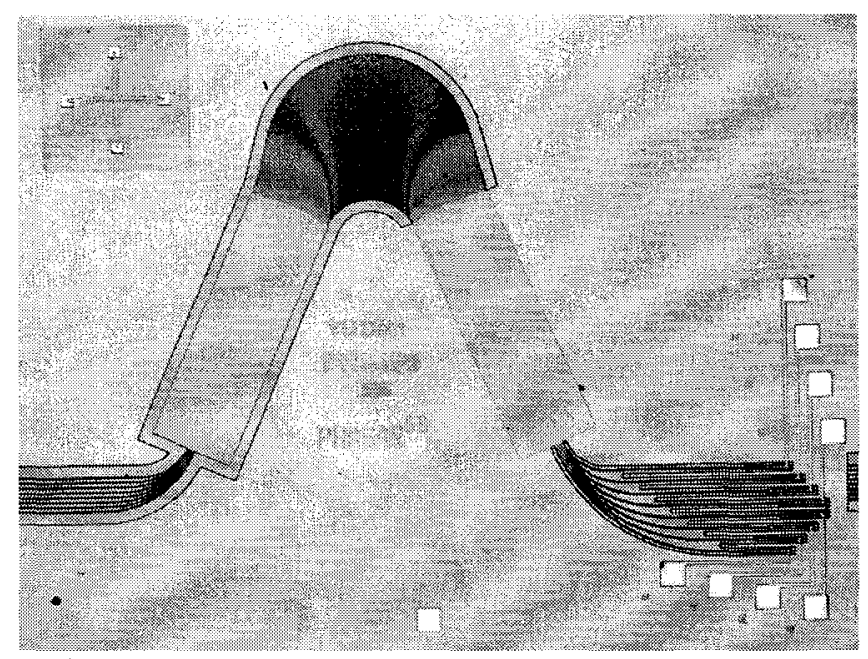

Fig. 1. PHASAR with integrated detectors.

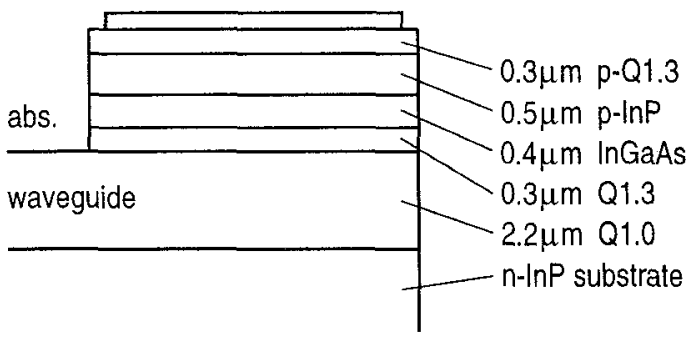

Fig. 2. Photodetector layers.

\section{FABRICATION}

After Low-Pressure MOVPE growth, processing starts with definition of the detector mesas using selective wet chemical etching. In the same step, the detector layers are removed from the area designated for the PHASAR. Outside this area the detector layers are left in place to absorb scattered light. Next the p-metallisation is fabricated, which consists of $6 \mu \mathrm{m}$ wide strips on top of the detector mesas, connected to $100 \times 100 \mu \mathrm{m}$ wide bond pads by $10 \mu \mathrm{m}$ wide leads. Prior to deposition of the metallisation, a $\mathrm{Si}_{3} \mathrm{~N}_{4}$ isolation layer is deposited. Fabrication of the PHASAR is performed by means of direct electronbeam writing techniques and reactive ion etching. Finally, the wafer is thinned and the $\mathrm{n}$-metallisation is deposited.

The wafer is cleaved into dies of $3.5 \times 3 \mathrm{~mm}^{2}$, and an AR coating is applied to the front facet. Subsequently, the device is mounted on a Si submount and a $6 \times 6 \mathrm{~mm}^{2}$ carrier with 8 contacts. Fibre-chip coupling is accomplished by means of a lensed fibre, having a $12.5 \mu \mathrm{m}$ radius of curvature allowing less than $1 \mathrm{~dB}$ coupling loss. The fibre is actively aligned to the appropriate input waveguide, and fixed by soldering it on a stud mounted on a base plate in front of the carrier. Finally, the fibre-chip assembly is mounted on a Peltier cooler inside a 14-pin industry-standard Butterfly package (see Fig. 3).

\section{RESULTS}

Figure 4 shows the response at $1 \mathrm{~mW}$ unpolarised input power of an 8-channel device before and after packaging. (Before packaging, data were obtained by positioning a lensed fibre--different from the one used in the module-in front of an input waveguide using a piezo controlled X-Y-Z translation stage.) The performance of the module is only $1 \mathrm{~dB}$ below that of the unpackaged device, which can be attributed to a larger coupling loss in the module. For six channels, the crosstalk is below $-20 \mathrm{~dB}$, one channel has a low reponse, and another one has a high background. This is due to an electrical leakage path from the detector bond pad to the absorber regions surrounding the PHASAR. Finally, all channels have a TE-TM shift of less than $0.2 \mathrm{~nm}$.

This device has a rather large insertion loss of $21 \mathrm{~dB}$, as is determined from Fig. 4 by assuming a detector with $100 \%$ internal quantum efficiency. This is accounted for by the $8 \mathrm{~dB}$ insertion loss of the PHASAR (which is measured from a device which had the detectors cleaved off), and the $-13 \mathrm{~dB}$ external efficiency of the detector (which is obtained 


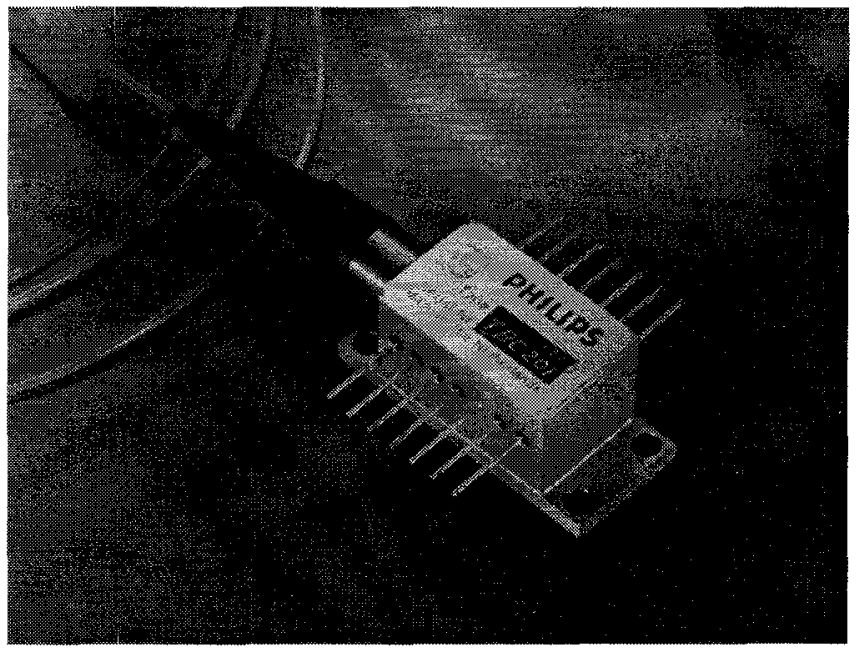

Fig. 3. 8-Channel Butterfly-type PHASAR module.
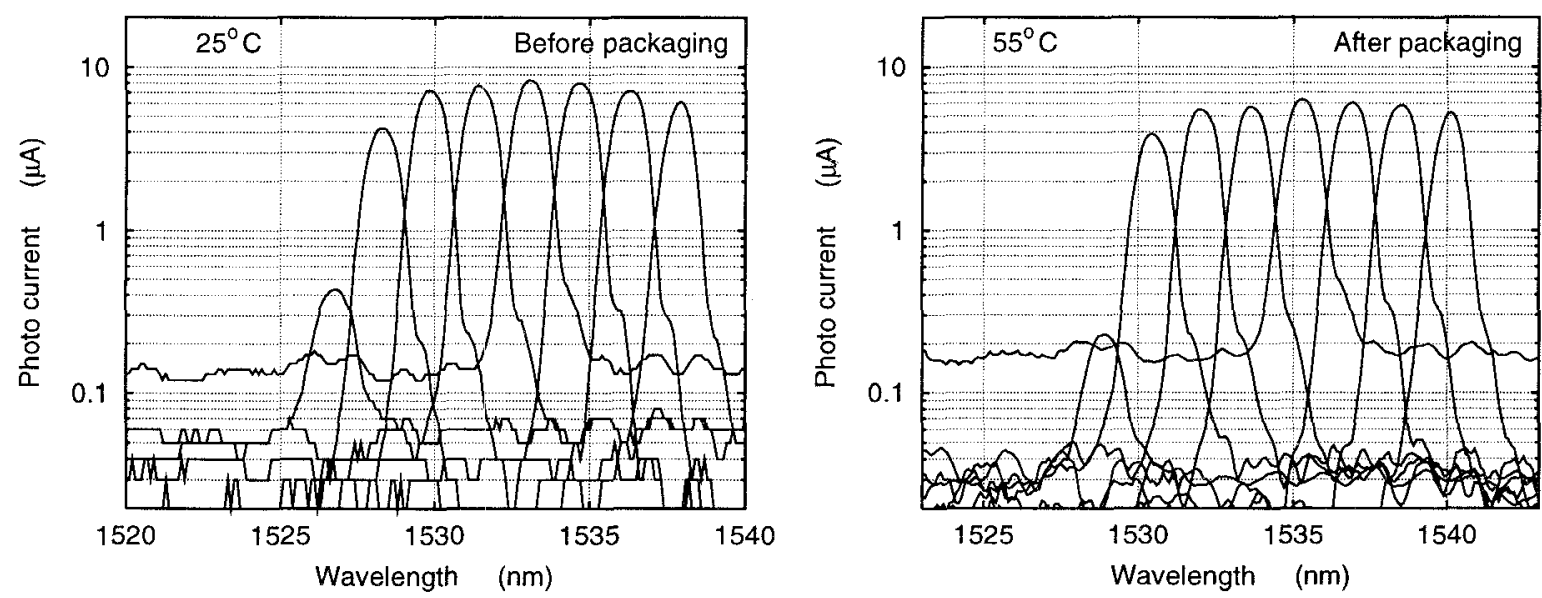

Fig. 4. Photo current versus wavelength at $1 \mathrm{~mW}$ input power, before (left) and after packaging (right).

The channel spacing is $200 \mathrm{GHz}$, as designed.

from the array of detectors cleaved off the PHASAR). The low efficiency of the detectors has been tracked down to a problem with the $\mathrm{Si}_{3} \mathrm{~N}_{4}$ isolation layer, which breaks down at reverse voltages above $1 \mathrm{~V}$. In addition, this problem is reponsible for the large background of one of the channels. Separately fabricated reference photodiodes having a good $\mathrm{Si}_{3} \mathrm{~N}_{4}$ layer exhibit an external efficiency of $-3 \mathrm{~dB}$ at a reverse voltage of $5 \mathrm{~V}$, including coupling and waveguide loss.

In addition to the 8-channel polarisation independent device, one of the devices reported in Ref. [3] has been packaged as well. As shown in Fig. 5, tuning over more than $4 \mathrm{~nm}$ has been obtained with virtually no performance degradation, by changing the chip temperature using the built-in Peltier cooler.

\section{CONClusions}

First results have been presented of PHASAR-based wavelength demultiplexers with integrated photodetectors which are packaged in industry-standard Butterfly-type modules. 8-Channel nearly polarisation-independent operation has been demonstrated, as well as tuning of the channels over more than $4 \mathrm{~nm}$. 


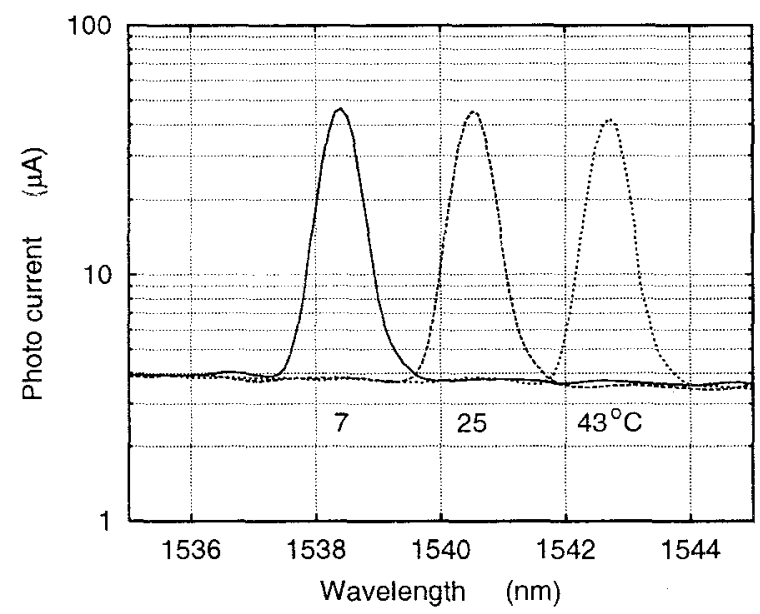

Fig. 5. Photo current versus wavelength at $1 \mathrm{~mW}$ input power for 1 channel at 3 temperatures.

The contributions of $T$. van Dongen (crystal growth), M. Vermeulen-Hartjes (device coating), and A. van Leerdam (device mounting) are gratefully acknowledged. Part of this work has been supported by the ACTS AC028 TOBASCO project.

\section{REFERENCES}

[1] C. Cremer, N. Emeis, M. Schier, G. Heise, G. Ebbinghaus, and L. Stoll, "Grating spectrograph integrated with photodiode array in InGaAsP/InGaAs/InP," IEEE Photon. Technol. Lett., vol. 4, pp. 108-110, Jan. 1992.

[2] J.B. Soole, A. Scherer, Y. Silberberg, H.P. LeBlanc, N.C. Andreadakis, C. Caneau, and K.R. Poguntke, "Integrated grating demultiplexer and pin array for high-density wavelength division multiplexed detection at $1.5 \mu \mathrm{m}$," Electron. Lett., vol. 29, pp. 558-560, Mar. 1993.

[3] M.R. Amersfoort, C.R. de Boer, B.H. Verbeek, P. Demeester, A. Looyen, and J.J.G.M. van der Tol, "Lowloss Phased-Array based 4-channel wavelength demultiplexer integrated with photodetectors," IEEE Photon. Technol. Lett., vol. 6, pp. 62-64, Jan. 1994.

[4] J.B.D. Soole, M.R. Amersfoort, H.P. Leblanc, N.C. Andreadakis, A. Rajhel, and C. Caneau, "Polarisationindependent monolithic eight-channel 2nm spacing WDM detector based on compact arrayed waveguide demultiplexer," Electron. Lett., vol. 31, pp. 1289-1291, Jul. 1995.

[5] C.A.M. Steenbergen, C. van Dam, A. Looijen, C.G.P. Herben, M. de Kok, M.K. Smit, J.W. Pedersen, I. Moerman, R.G.F. Baets, and B.H. Verbeek, "Compact low-loss $8 \times 10$ Polarisation independent WDM receiver," Proc. 22nd Eur. Conf. on Opt. Comm. (ECOC '96), Oslo, Sep. 15-19, paper Mo.C4.1.

[6] C.A.M. Steenbergen, L.C.N. de Vreede, C. van Dam, T.L.M. Scholtes, M.K. Smit, J.L. Tauritz, J.W. Pedersen, I. Moerman, B.H. Verbeek, and R.G.F. Baets, "Integrated $1 \mathrm{GHz}$ 4-channel InP PHASAR based WDM-receiver with Si bipolar frontend array," Proc. 21st, Eur. Conf. on Opt. Comm. (ECOC'95), Brussels, Sep. 17-21, paper Tu.A.3.4.

[7] S. Chandrasekhar, M. Zirngibl, A.G. Dentai, C.H. Joyner, F. Storz, C.A. Burrus, and L.M. Lunardi, "Monolithic eight-wavelength demultiplexed receiver for dense WDM applications," IEEE Photon. Technol. Lett., vol. 7, pp. 1342-1344, Nov. 1995.

[8] E. Gini, M. Balser, W. Hunziker, and H. Melchior, "Packaged 2.5Gb/s 4-channel WDM receiver module with InP grating demultiplexer and pin-JFET receiver array," Proc. 21st Eur. Conf. on Opt. Comm. (ECOC '95), Brussels, Sep. 17-21, paper Tu.A.3.3.

[9] B.H. Verbeek, A.A.M. Staring, E.J. Jansen, R. van Roijen, J.J.M. Binsma, T. van Dongen, M.R. Amersfoort, C. van Dam, and M.K. Smit, "Large bandwidth, polarization independent, and compact 8 channel PHASAR demultiplexer/filter," OFC/IOOC'94 Techn. Digest, San Jose, CA, Feb. 20-25, post-deadline papers, pp. 63-66, 1994. 